Estar entre mundos e ao mesmo tempo não pertencer a nenhum. O caso da literatura em língua alemã produzida no Brasil no século XIX | 151

\title{
ESTAR ENTRE MUNDOS E AO MESMO TEMPO NÃO PERTENCER A NENHUM. O CASO DA LITERATURA EM LINGUA ALEMÃ PRODUZIDA NO BRASIL NO SECULO XIX
}

Gerson Roberto Neumann ${ }^{1}$

Resumo: Com o presente texto objetiva-se refletir sobre uma possível "Breve história da literatura de expressão alemã no Brasil. Uma literatura sem local definido e a procura por uma definição”. Trata-se de uma produção literária em língua alemã, produzida e publicada em língua alemã. Propõe-se a discussão de conceitos como região, o local da cultura, assim como função da literatura. Está em questão uma literatura sem local definido, entre dois contextos, entre a literatura alemã e a brasileira. Palavras-chave: literatura brasileira; literatura alemã; local; não-local

Zusammenfassungo: Das Nachdenken über eine mögliche "Kleine Geschichte der deutschsprachigen Literatur in Brasilien. Eine Literatur ohne festen Platz und die Suche nach einer Definition" ist das Ziel dieses Beitrags. Es geht um eine literarische Produktion in deutscher Sprache, die in Brasilien greschrieben und veröffentlciht wurde. Diskutiert werden Begiffe wie Region, die Verortung der Literatur sowie die Funktion der Literatur. Es geht um eine ortlose Literatur, zwischen zwei Kontexten, zwischen der deutschen und der brasilianischen Literatur.

Stichwörter: Brasilianische Literatur; Deutsche Literatur; Ort; Nicht-Ort.

\section{Introdução}

Pretende-se tratar aqui de uma literatura que existe no Brasil, localizada temporalmente na segunda metade do século XIX, estendendose até o início da Segunda Guerra Mundial. Em questão está a produção literária em língua alemã no Brasil; uma literatura que existe, ela está aí, em arquivos e acervos, mas que ao mesmo tempo não existe por não se saber dela, ou muito pouco. No presente texto, pretende-se trazer à reflexão o tema "Uma literatura entre mundos, contudo sem espaço definido. O caso da literatura em língua alemã no Brasil”, projeto

\footnotetext{
${ }^{1}$ Prof. Adjunto UFRGS - gerson.neumann@gmail.com
} 
desenvolvido há longo tempo na minha caminhada, desde a formação acadêmica, aprofundado em forma de Pós-Doutorado junto à Universität Potsdam, na Alemanha, entre 2014-2015 . O que se quer com o presente texto é chamar a atenção dos leitores - principalmente dos vinculados ao contexto de ensino de língua alemã no Brasil (o que pressupõe uma atenção ao cenário cultural inerente ao ensino de uma língua estrangeira) - para a necessidade de se trabalhar e pesquisar esta literatura que está esquecida em arquivos de universidades, institutos e residências particulares. Trata-se de uma literatura que precisa ser vista e ter voz.

Como resultado do longo período dedicado a pesquisas em torno da literatura produzida e publicada em língua alemã no Brasil, compreendendo-se naturalmente reflexões teóricas subjacentes a todo o cenário de imigração no Brasil e o desenvolvimento de uma identidade nacional e cultural de um grupo aparentemente homogêneo, mas que na verdade possui muito pouco de uma homogeneidade muitas vezes pregada, pretendemos trazer, neste momento, à discussão: primeiro, a literatura em língua alemã produzida e publicada no Brasil; segundo, a literatura em língua alemã no Brasil como uma literatura entre duas culturas ou entre mundos; terceiro, o (possível) local desta literatura; quarto, a análise de um poema que caracteriza a referida literatura, com o intuito de trazer um exemplo para, de alguma forma, aproximar a literatura aqui em questão do leitor.

\section{Uma literatura em língua alemã produzida e publicada no Brasil?}

Trata-se aqui de uma literatura de fundo sócio-histórico; no caso, o contexto da imigração alemã no Brasil. Especialmente em relação à imigração alemã, é necessário lançar um olhar mais atento ao século XIX. Os primeiros imigrantes chegaram ao Brasil nas primeiras décadas do referido século com apoio (principalmente financeiro) do então governo imperial.

Devido ao cenário político da época, a segunda década do século XIX, os imigrantes não poderiam ser espanhóis, o que se explica devido às longas fronteiras com os países de língua espanhola. Holandeses e franceses eram uma opção impossível devido às antigas invasões no Nordeste brasileiro, assim como ao fato de estas nações já possuírem

\footnotetext{
${ }^{2}$ Vide a página do Projeto POINTS - Potsdam International Network for TransArea Studies - http://www.uni-potsdam.de/tapoints/?p=1693.
} 
Estar entre mundos e ao mesmo tempo não pertencer a nenhum. O caso da literatura em língua alemã produzida no Brasil no século XIX | 153 colônias na América do Sul, o que poderia se tornar um risco para a manutenção dos limites nacionais. Os ingleses não entravam em questão por causa de seus contatos políticos próximos com Portugal. A partir desse cenário político, a emigração de alemães para o Brasil parecia favorável. Havia ainda outro fator em prol da imigração de alemães no Brasil: o casamento do príncipe regente brasileiro, Dom Pedro I, com a filha da casa dos Habsburgos da Áustria, Dona Leopoldina.

Em meio a esse cenário, ocorre a entrada dos primeiros imigrantes alemães no Brasil. A produção literária por parte dos integrantes das primeiras ondas dá-se em forma de relatórios e de cartas, ainda não existindo espaço para a produção de uma literatura que possa ser vista como arte (de uma literatura de ficção, por exemplo).

A partir de 1850, ingressam no Brasil também emigrantes que deixavam sua terra natal, principalmente, por questões políticas. Em números, trata-se de um grupo bastante menor em comparação ao número total de imigrantes; no entanto, com a sua chegada ocorre um crescimento considerável no que tange à política e à cultura no contexto imigratório. Muitos desses novos imigrantes atuaram na Revolução de $1848^{3}$ com o objetivo de criar uma unidade nacional alemã e, com a derrota, tiveram que deixar sua pátria. A maior parte destes revolucionários vendeu sua força de trabalho como soldado ou mercenário, emigrando para os Estados Unidos; outros procuraram a América do Sul e, destes, muitos atuaram como soldados do lado brasileiro, em guerra com o ditador argentino Juan Manuel de Rosas na Guerra de La Plata. ${ }^{4}$

Os mercenários tornaram-se figuras emblemáticas no contexto imigratório brasileiro, de modo que o grupo passou a ter um significado especial: eles são chamados de Brummer, um conceito que se fixou na História da imigração alemã no Brasil. Segundo Kreutz (1991), a definição

\footnotetext{
${ }^{3}$ A Deutsche Revolution 1848/49 - As Revoluções de 1848 nos Estados alemães também chamada de Revolução de Março - é marcada por uma série de protestos coordenados e rebeliões nos Estados da Confederação Germânica, incluindo o Império Austríaco. As revoluções salientavam o pangermanismo, e era enfatizado o descontentamento popular com a tradicional estrutura marcadamente autocrática dos 39 Estados independentes da Confederação, que havia herdado o território alemão do Sacro Império Romano-Germânico. Sobre a História alemã do século XIX, ver RÜRUP, R. 1984; NIPPERDEY, T. 1985.

${ }^{4}$ Mais em relação a esse tema, vide Cem anos de germanidade no Rio Grande do Sul. Trad. Arthur B. Rambo. São Leopoldo: UNISINOS, 1999, p. 151-154.
} 
Brummer quer dizer, em primeiro lugar, "o que causa zunido, barulho;" (KREUTZ, L. 1994, p. 22) eles são resmungões que questionam tudo que se lhes é oferecido. Em segundo lugar, os mercenários são chamados de Brummer por causa do barulho que faz o Patacão $0^{5}$ sobre a mesa, dinheiro pelo qual trabalhavam.

Nesse contexto, foi fundado o primeiro jornal para as comunidades alemãs no Brasil, em 1852: Der Kolonist. Seu editor foi o diretor do diário O Mercantil, José Gomes Cândido, curiosamente um empreendedor de origem não germânica. Esse primeiro jornal, no entanto, teve uma breve existência. Os temas abordados pelo jornal giravam em torno do comércio, da indústria e da agricultura e também se traduzia as principais leis do império. O objetivo do jornal era de ampliar o tão relevante conhecimento geral dos colonos para uso no dia a dia brasileiro. $^{6}$

O segundo jornal - Der deutsche Einwanderer - existiu primeiramente no Rio de Janeiro. Por questões financeiras, foi transferido para Porto Alegre no ano de 1854 pelo Dr. Kiekbach, onde foi comprado por Theobald Jaeger. O primeiro redator-chefe do jornal foi Carl Jansen, também um Brummer. Da mesma forma, este jornal teve vida efêmera, sendo fechado em 1861. Contudo, no mesmo ano as instalações foram compradas por um grupo de comerciantes, entre os quais se encontravam integrantes da antiga Legião Alemã, portanto, Brummer. Dessa iniciativa, resultou o primeiro jornal em língua alemã que desenvolveu um importante e longo trabalho: Deutsche Zeitung, que existiu até 1917. Importantes redatores trabalharam nele, entre os quais Karl von Koseritz, dentre os imigrantes de orientação liberal o mais conhecido devido à sua atuação no cenário literário-político. $\mathrm{O}$ jornal destacou-se pela sua postura liberal e anticlerical.

Depois dessa primeira experiência exitosa, a atividade jornalística teuto-brasileira intensificou-se; outros jornais surgiram, também fora da capital do Rio Grande do Sul, Porto Alegre. Em São Leopoldo, então o local com a maior concentração de imigrantes, Julius Curtius fundou, no ano de 1867, o almanaque Der Bote. Amtliches Blatt für St. Leopold und die Colonien. Esse jornal era igualmente de tendência anticlerical, mas, devido

\footnotetext{
${ }^{5}$ Uma moeda do período imperial brasileiro.

${ }^{6}$ Ver FAUSEL, 1956, p. 225.
} 
Estar entre mundos e ao mesmo tempo não pertencer a nenhum. O caso da literatura em língua alemã produzida no Brasil no século XIX | 155

a divergências políticas relativas à colonização alemã no Brasil, tomou um posicionamento de oposição em relação ao Deutsche Zeitung. ${ }^{7}$

É importante ressaltar, contudo, que a cena política não abria espaço para uma convivência harmoniosa nesse novo contexto, e por consequência no cenário cultural, principalmente depois da chegada dos Brummer. Devido ao fato de este grupo ser formado basicamente por imigrantes de posição política liberal, explicando-se por isso a sua oposição ao tradicionalismo religioso (principalmente frente ao católico, mas também ao evangélico-luterano), iniciou-se um movimento antiBrummer que se fez perceber claramente no cenário editorial. Dessa forma, as igrejas católica e luterana tornaram-se oposição frente aos ideais liberais. O ganhador, permitindo-nos afirmá-lo dessa forma, nessa disputa foi o cenário político-cultural da imigração alemã no Brasil, pois o conflito se fez refletir frutífero na produção literária.

Depois de longo período de discussões e iniciativas, em 1899, foi publicada no Editorial do suplemento literário Unterm Südlichen Kreuz, do jornal Deutsche Post uma importante reflexão sobre a publicação de textos literários em língua alemã "sob uma outra constelação" em um outro "contexto." Foi enfatizado o fato de que essa produção também deveria ser acessível àqueles que a quisessem ler, no Brasil. Segundo o editor e também escritor Wilhelm Rotermund, produção já existia, o que havia até então era a falta de opções onde se pudesse publicar, como é possível ler na passagem a seguir:

Passamos aqui pela encantadora natureza e por fim, nós mesmos ficamos encantados. Tivéssemos nós alguém que abrisse os nossos olhos para as inúmeras belezas e nô-las esclarecesse! Não é correto que se nos guiem sempre sob a Ursa Maior do céu do Norte, quando habitamos sob o Cruzeiro do Sul, e festejemos Natal em neve e gelo, quando mal sabemos conviver com o calor [...]. Seria bom e certamente também útil se tivéssemos uma série de retratos sérios e alegres das pessoas e da terra, sob a qual o Cruzeiro do Sul faz a sua trajetória silenciosa. Muitos, isto eu sei, já fizeram tal estudo, mas deixaram-no descansar na pasta,

${ }^{7}$ FAUSEL, E. 1956. Segundo Fausel, o jornal foi publicado até o ano de 1877. 
porque, segundo eles, não havia emprego para este tipo de esboço. ${ }^{8}$

\section{A literatura em língua alemã no Brasil. Literatura entre mundos?}

A discussão em torno da literatura em língua alemã deixada pelos imigrantes alemães e seus descendentes é, sem dúvida, de grande importância. No ano de 2014 comemoram-se os 190 anos da imigração alemã no Brasil. No entanto, o que se produziu na área da literatura encontra-se, em grande parte, infelizmente, esquecido em arquivos. Isso (também) deveria e mereceria ser recuperado e rememorado nessa ocasião! Espera-se que em alguns anos, em breve, seja possível escrever a História da Literatura de Expressão Alemã no Brasil.

Trata-se aqui de uma literatura sem pertencimento, que se localiza entre a Alemanha e o Brasil. Em questão está, portanto, uma literatura existente no Brasil, cujo local de identificação ainda não pode ser definido, e que talvez não tenha que ser definido, por se tratar de uma literatura que existe em meio a duas culturas. Ela não é tida como brasileira porque foi publicada principalmente em língua alemã e direcionada a um grupo leitor limitado - mas ainda assim um grupo leitor brasileiro falante de língua alemã. Apesar de publicada em língua alemã, nela são abordados temas da realidade brasileira - trata-se do cotidiano dos imigrantes alemães. Esse fato, por sua vez, leva ao não reconhecimento dessa produção como literatura alemã, pois ela não é

${ }^{8} \mathrm{O}$ chamamento foi publicado no Editorial do suplemento "Unterm südlichen Kreuz” em 4 de janeiro de 1899. Poder-se-ia citar aqui ainda outros almanaques e jornais; esse, contudo, não é o objetivo nesse momento. Sobre o assunto, BONOW (1991) publicou uma detalhada dissertação de mestrado. Nestes almanaques e jornais foi publicada a literatura analisada nas pesquisas que vêm sendo desenvolvidas. "Wir gehen hier durch die zauberhafte Natur zuletzt selber verzaubert hindurch. Hätten wir doch nur jemanden, der unsere Augen öffnete für die vielen Schönheiten und sie uns erklärte! Es ist doch nicht recht, da $\beta$ man uns immer dem Grossen Bären des nordischen Himmels führt, wo wir unter dem südlichen Kreuz wohnen (...). Schön wär's schon und auch gewiß nützlich, wenn man in einer Reihe ernster und heiterer Bilder das Land, über welchem das Kreuz des Südens seine stillen Kreise zieht, und auch die Menschen darin abkonterfeien würde. Mancher, das weiß ich, hat schon solche Zeichenstudien gemacht, aber sie in der Mappe ruhen lassen, weil er für derartige Skizzen keine Verwendung hatte." Tradução nossa. 
Estar entre mundos e ao mesmo tempo não pertencer a nenhum. O caso da literatura em língua alemã produzida no Brasil no século XIX | 157 mais escrita na Alemanha e, por sua vez, tornou-se de certa forma desconhecida na Alemanha. Além disso, é importante mencionar que essa literatura paulatinamente incorporou termos da língua local, o que levou a um distanciamento ainda maior da geograficamente já distante Alemanha.

A partir de um estudo mais aprofundado e mais atento dessa literatura, pretende-se dar, portanto, uma importante contribuição para a discussão, ampliação e o aprofundamento de questões relativas ao tema, destacando conceitos como espaço, local e minorias. A discussão científica atual possibilita uma análise apropriada e profícua da expressão literária desse grupo imigrante nada homogêneo. No presente artigo, pretende-se, no entanto, analisar a literatura do imigrante alemão como uma produção de um grupo que produz ficção na sua língua materna em um cenário linguístico distinto. Com o passar do tempo, o cenário linguístico deixa perceber que a um processo de hibridização linguísticocultural está em curso.

São muitas as perguntas que surgem, quando se reflete de modo mais aprofundado sobre a questão, como, por exemplo:

1) A literatura dos imigrantes alemães e seus descendentes pode ser tomada como literatura de um grupo? Em caso afirmativo, e observando-se as diferenças inerentes a cada um, essa literatura poderia pertencer a uma história da literatura (brasileira/alemã)? Como isso se daria?

2) Ao se falar, conforme o romanista Ottmar Ette, de uma "Literatura sem local definido," seria desnecessário tratar de uma literatura brasileira ou alemã? Ainda segundo Ette, a função da literatura - assim como da filologia - é tornar audível o que há muito valia como perdido (ETTE, 2005, p. 59). Seria esse também o caso da literatura aqui em questão?

3) Que função poderia desempenhar a tradução nesse caso? Que as línguas ocupam um lugar de destaque nessa produção está claro. Até que ponto a importância das línguas e da tradução deve ser inserida nesse contexto da discussão?

4) As pesquisas e os levantamentos da literatura alemã publicada no Brasil e que hoje se encontra basicamente em arquivos tornariam essa produção do século XIX, mas de grande importância para a compreensão 
da história da formação do Brasil e da Alemanha, mais acessível, permitindo assim que mais pesquisadores possam estudá-la. ${ }^{9}$

A conclusão a que se chega nesse momento é a de que o estudo da produção literária em questão, a literatura de expressão alemã produzida no Brasil, deve ser estudada por especialistas que transitem, preferencialmente, por um contexto de abordagem multicultural, pois o corpus por si só já é o resultado de um trânsito, de um movimento de pessoas.

\section{O local na literatura}

A relevância do local na literatura há tempo fixou seu lugar nas discussões em áreas como as Ciências da Cultura e da Literatura. Nesse sentido, com essa discussão, pretende-se refletir sobre questões em torno da identidade e suas diversas formas de desdobramento.

A partir de uma perspectiva da literatura alemã, vem ao encontro da discussão uma importante obra de Ottmar Ette, ZwischenWeltenSchreiben. Literaturen ohne festen Wohnsitz [EscreverEntreMundos. Literaturas sem local definido] (2005). O referido autor trabalha, entre outros temas, "Literatur in Bewegung" [Literatura em movimento] (2001) e o "ÜberlebensWissen" [SaberSobreViver] literário (2004), sempre com o objetivo de refletir formas de expressão literária em meio a passagens e à procura por aceitação e na luta pela eliminação de todas as formas de preconceitos. Em relação a isso, pode-se ler na apresentação do livro ZusammenLebensWissen. List, Last und Lust literarischer Konvivenz im globalen Maßstab [SaberViverJunto. Astúcia, ônus e anseio da convivência literária em escala global]:

${ }^{9}$ Em relação ao trabalho de pesquisa em arquivos e acervos, cabe mencionar o projeto de digitalização dos principais acervos no Brasil que guardam almanaques e jornais publicados em língua alemã pelos imigrantes alemães e seus descendentes no Brasil. O referido projeto é encabeçado pelo Prof. Dr. Paulo A. Soethe, da UFPR e conta com a parceria de instituições brasileiras, como a Fundação Biblioteca nacional, e alemães, como o Iberoamerikanisches Institut, de Berlim. Além disso, estamos em contato com colegas de países que também tiveram uma imigração de alemães (da Argentina, dos USA). Ver Prof. Dr. Paulo A. Soethe, Germanistik in Südbrasilien. p. 531-534, 2010. 
Estar entre mundos e ao mesmo tempo não pertencer a nenhum. O caso da literatura em língua alemã produzida no Brasil no século XIX | 159

A pergunta sobre como nós conseguimos viver entre diferentes culturas, religiões, línguas e atribuições identitárias é, na verdade, uma das perguntas fundamentais para as quais as mais diferentes tradições literárias do mundo, [...] desde a epopeia de Gilgamesch e suas Mil e Uma Noites, têm procurado respostas. ${ }^{10}$

Em relação à literatura dos imigrantes alemães, também existe um convívio, que em parte é o reflexo de duas culturas, ou dito de outra forma, é a expressão de uma cultura que passou a existir dentro de outra, assumindo logo muitos elementos da cultura dela. Por isso, a literatura em questão pode ser tomada como um caso de hibridismo e como uma terceira forma de identificação.

Além dos estudos críticos de Ette, são de extrema importância $O$ local da cultura, de Homi Bhabha (2000), especialmente quando se trata de "Estereótipo, discriminação e o discurso do colonialismo" e Stuart Hall (2009) quando se trata Da diáspora. Identidades e mediação cultural, assim como os trabalhos de Ortrud Gutjahr (2012), principalmente em relação aos estudos da Transculturalidade e intermedialidade na Germanistica em tempos globais ${ }^{11}$ e de Andrea Pagni, ${ }^{12}$ nos seus estudos sobre Processos de Tradução Cultural e sobre Literatura de Viagem.

Importante também é o diálogo com o trabalho da Profa. Dra. Celeste H. M. Ribeiro de Sousa (2004), da USP, no qual ela se ocupa da Imagem do outro nas relações literárias entre Brasil e Alemanha. Ribeiro de Sousa também é a coordenadora do grupo de pesquisa RELLIBRA, que tem como objetivo trazer a literatura em língua alemã publicada no Brasil

\footnotetext{
10 "die Frage, wie wir zwischen unterschiedlichen Kulturen, Religionen, Sprachen und Identitätszuschreibungen zusammenleben können, ist freilich eine der Grundfragen, auf welche die verschiedensten Traditionen der Literaturen der Welt [...] seit dem Gilgamesch-Epos und seit Tausendundeine Nacht immer wieder neue Antworten gesucht haben." Tradução nossa. Ver http://www.unipotsdam.de/romanistik/ette/konvivenz.html.

11 Mais dados sobre a bibliografia de Gutjahr, ver http://www.slm.unihamburg.de/ifg2/personal/Ortrud_Gutjahr.html.

${ }^{12}$ Mais dados sobre a bibliografia de Pagni, ver http://www.romanistik.phil.unierlangen.de/institut/mitarbeiterinnen/pagni.shtml\# reiseliteratur.
} 
a uma plataforma online para, com isso, torná-la mais acessível ao leitor e pesquisador. $^{13}$

Na produção literária em questão, é importante enfatizar que não se trata de uma produção de imigrantes com pouca experiência ou iletrados (o que também não deveria ser um elemento excludente por si só!), mas de muitos autores de formação acadêmica. Entre eles figuram, por exemplo, Georg Knoll (1861-1940 - estudou Botânica em Geisenheim), Paul Aldinger (1869-1944 - Doutor em Filosofia), Wilhelm Rotermund (1843-1925 - Doutor em Filosofia), e dentre eles o talvez mais ilustre e mais importante: Karl von Koseritz (1830-1890), que desempenhou importante trabalho político-cultural no Brasil.

A germanista Marion Fleischer (1981) busca definir essa literatura heterogênea dentro de sua homogeneidade, no entanto acaba por se concentrar nos objetivos dos autores estudados por ela. Conforme Fleischer, a referida literatura tem por objetivo contribuir para a manutenção da língua alemã e das tradições. Ao mesmo tempo, no Brasil a literatura assumiria como que uma função pedagógica de transmissão da herança cultural. Em consonância com esse objetivo, ter-se-ia tentado invocar no imigrante e seus descendentes um 'sentimento nacional' no sentido de se amalgamar o amor à terra natal e a dedicação à sua nova pátria. Segundo a estudiosa, aqui está o princípio da explosão emocional que se apresenta em muitos textos da literatura de expressão alemã no Brasil (FLEISCHER, 1981, p. 26-27).

Em relação a essa discussão, a antropóloga Giralda Seyferth (2004) cita o sociólogo Emilio Willems ${ }^{14}$, que já em 1940 escreve sobre a literatura de expressão alemã no Brasil e lança mão do conceito de 'cultura híbrida' para reforçar a particularidade da cultura teuto-brasileira. Com isso ele busca superar algumas limitações dos conceitos de assimilação e de aculturação nos processos de migração vigentes à época. O hibridismo cultural contém o pré-requisito da duplicidade que resulta do contato dos imigrantes e de seus descendentes com o meio, a sociedade e a cultura no Brasil, o que se expressa pela aplicação analítica

\footnotetext{
${ }^{13}$ A Profa. Dra. Celeste Ribeiro de Sousa também coordena o Projeto de Pesquisa "Literatura Brasileira de Expressão Alemã" no Grupo de Pesquisa RELLIBRA (Relações Linguísticas e Literárias Brasil-Alemanha). Ver www.rellibra.com.br. ${ }^{14}$ Emilo Willems (1905-1997) foi um cientista social alemão, radicado no Brasil. Ver Aculturação dos alemães no Brasil, São Paulo, 1946.
} 
Estar entre mundos e ao mesmo tempo não pertencer a nenhum. O caso da literatura em língua alemã produzida no Brasil no século XIX | 161 da categoria "teuto-brasileiro" (Deutsch-Brasilianisch, Deutschbrasilianer ou Deutschbrasilianisch) (SEYFERTH, 2004).

Como se pode perceber, o hífen, empregado em muitas definições identitárias, pode agregar características; mas também pode ser marcador de uma marginalização, de uma exclusão dos dois grupos conectados por ele. ${ }^{15}$ Nesse caso, também é importante mencionar os estudos de Ette, pois ele trabalha a produção literária impossível de ser definida espacialmente, a qual muitas vezes também é unida a dois ou mais lugares com o já mencionado hífen. Conforme o autor, literatura e ciência, e aqui poder-se-ia mencionar o caso da literatura teuto-brasileira, repousam sobre um grande número de localizações espaciais e por isso correm o risco de não serem percebidas e refletidas (ETTE, 2001, p. 21).

No caso dos imigrantes alemães no Brasil - fundamentalmente um homem do campo - tem-se o caso de um 'marginal man' (SEYFERTH, 2004), que vivia praticamente 'isolado' na sua língua e nas localidades organizadas e planejadas (regiões de vales) para ele. Ele deve cultivar essas terras de modo que nelas pudesse ocorrer um constante desenvolvimento em pequenos estabelecimentos. Nesse sentido, Fleischer afirma que os grupos migratórios que se estabeleceram no Brasil são caracterizados pelo isolamento cultural. Segundo Fleischer, as causas para tal são: a dificuldade de comunicação devido às línguas ou às diferentes tradições ou por vezes também devido às grandes distâncias entre as diferentes colônias entre si, assim como entre elas e os centros urbanos (FLEISCHER, 1981, p. 25). Como os imigrantes são homens marginais que vivem entre mundos, assim a literatura também parece ter sido tomada formalmente como menor. Ela foi tachada de ser direcionada a um público não letrado - apenas a pessoas com parca alfabetização e, além disso, com poucos conhecimentos. Uma demonstração da "ambivalência," da "dualidade" e do particularismo geralmente atribuído a descendentes de imigrantes. ${ }^{16}$ Pode-se afirmar isso, pois, apesar de ele ser um homem inserido no seu contexto, trata-se de alguém que, ainda assim, se desloca entre dois mundos e duas línguas e que se encontra em um processo de construção híbrida, pertencente ao mesmo tempo a duas culturas, com trânsito nelas, mas também não pertencente plenamente a

\footnotetext{
${ }^{15}$ Ao tratar da hifenização, refiro-me a BHABHA, 2000, p. 301s.

16 SEYFERTH, 2004. Ver também KUDER, 1936/37; HUBER, 1993, 2002, 2003.
} 
ambas, existindo sempre uma defasagem. ${ }^{17} \mathrm{O}$ encontro de ambos os contextos fica claro em muitos poemas. Aqui foram selecionados apenas alguns de muitos (mas já bastante representativos) títulos de poemas: Heimat Brasilien, de Carlos H. Hunsche; São Paulo: de Rudolf Hirschfeld; Brasilia: de Dora Hamann; Der Einwanderer, de Karl Fouquet e Die Schmier. Ein riograndenser Straßenbild, de Karl Hermann. Este último será objeto de uma breve análise a seguir.

A escrita dos autores citados acima vale como composição simbólica da estruturação de uma "comunidade nacional" em um formato teuto-brasileiro ${ }^{18}$, sendo que os conteúdos culturais de etnicidade se caracterizam como marcadores de identidade do limite em relação à sociedade nacional. Esses símbolos exigem, porém, constantes reinterpretações com base no fato de que a incorporação e a adaptação desses elementos ocorrem em um novo contexto. Nesse caso, ocorre uma diluição do passado, do presente e do futuro para que uma continuidade transcendental da nação seja possível. Hall (2009) vê a nação como uma comunidade simbólica que surge a partir de um forte sentimento de identificação e lealdade. ${ }^{19}$ Nesse sentido, a literatura deve ser pensada não somente através da lógica da ambivalência (o indivíduo assim como a literatura entre duas culturas), como frequentemente ocorre.

\section{Exemplo de uma produção}

Pesquisar em arquivos e bibliotecas dá-nos a possibilidade de encontrarmos tesouros, achados de valor imenso e que precisam ser trabalhados e apresentados ao grande público. Como já afirmei anteriormente, há muito tempo dedico-me à pesquisa da literatura de expressão alemã no Brasil. Hoje pretendo compartilhar um desses achados.

Apresento a seguir o poema "Die Schmier. Ein riograndenser Straßenbild,” de Karl Hermann, publicado em 1925, no Kalender für die Deutschen in Brasilien, páginas 99-100.

\footnotetext{
${ }^{17}$ Nesse momento podemos dialogar com as palavras de Edward Said, no seu texto com tom bastante autobiográfico "Entre Mundos", do livro Reflexões sobre o exilio e outros ensaios.

${ }^{18}$ Ver SEYFERTH, 2004.

${ }^{19}$ Ver HALL, S. 2009, p. 54. Para ter uma ideia mais detalhada das comunidades alemãs no Brasil, ver NEUMANN, 2000.
} 
Estar entre mundos e ao mesmo tempo não pertencer a nenhum. O caso da literatura em língua alemã produzida no Brasil no século XIX | 163

Há alguns aspectos que se pretende apresentar em forma de uma análise que não aspira ser conclusiva, muito menos absoluta, mas trazer a literatura produzida, publicada e lida em língua alemã no Brasil da segunda metade do século XX.

Não sabemos se o autor Karl Hermann é alemão, imigrante alemão ou descendente de imigrantes alemães. Não se pretende aprofundar questões relativas à autoria. Enfatiza-se, no entanto, a publicação do poema em um dos anuários mais importantes do contexto de língua alemã no Brasil no referido período. Contudo, é importante chamar a atenção para o subtítulo do poema: "cena rio-grandense de rua" [Ein riograndenser Straßenbild]. Isso apresenta ao leitor onde que se localiza o local da narrativa. Estamos acompanhando um casal de trabalhadores rurais que se desloca ao meio urbano para vender a sua produção: a schmier.

O tom do poema é jocoso, o que percebe pelo vocabulário empregado pelo autor. O leitor acompanha o casal que entra no perímetro urbano da comunidade de Gravataí com uma carreta, puxado por bois, Ligeiro e Barros. Vem na carreta a mulher, Dona Loni, e acompanhando-a a pé o senhor Adomar. Amarrado à carreta, o cachorro acompanha o casal. Dona Loni e senhor Adomar deslocam-se ao que poderíamos chamar de "cidade" ou "centro urbano" para vender Schmier, certamente produção deles. Ao entrarem na localidade, são recebidos pelos interessados no produto, que o provam e se deliciam. Outros, como o moleque José, faz troça da schmier, dizendo que é como cera e que não vale nada. No entanto, muitos compram da schmier do casal; outros não. Como era usual no contexto migratório da época, o casal aproveita a ida à cidade para fazer compras, também de produtos especiais, como roupas. Assim, o dinheiro que ganhavam já era gasto com essas compras. O poema termina com um tom de moral, em que o boi Ligeiro recebe a voz, num tom de crítica à forma de vida do imigrante, pois ao voltar para casa, o casal se alimenta de feijão com farinha:

$\begin{array}{ll}\text { “Mein dummer Patrão } & \text { Meu pobre patrão } \\ \text { Verkauft na den João } & \text { Vende ao João } \\ \text { Die herrliche Schmier. } & \text { A divina schmier } \\ \text { Was ha ter dafür? } & \text { Para o que ganhar? } \\ \text { Bei Bohn' und Farin } & \text { A feijão e à farinha } \\ \text { So lebt er dahin! } & \text { Vive à míngua }\end{array}$




$\begin{array}{ll}\text { Farin und feijão } & \text { À farinha e a feijão } \\ \text { und keinen Tostão. } & \text { Sem um tostão. }\end{array}$

\section{"Mein Jummer Pattão verkauft an den João die berrliche $5 \mathrm{cbmier}$. Was bat er dafür?}

\section{Bei Bobn' und Farin so lebt er dabin! Sarin und Seijão und keinen Costão!}

O tom é jovial e o casal é descrito como simples e trabalhador, mas que parece não conseguir progredir a partir de seu trabalho, condenados à sina de meros coadjuvantes no cenário da imigração. $O$ mesmo tom poderia ser interpretado como pejorativo, vendo o produtor rural como pessoa simples, burra, trabalhador braçal, que produz um produto desejado pelas pessoas do meio urbano - a schmier -, mas que por isso não ganha o que deveria, pagando caro pelo que adquire a partir da venda de seus produtos. O boi Ligeiro usa o termo "dummer Patrão", que quer dizer "Patrão bobo" ou também "Patrão burro."

Anteriormente foi dito que a língua trazida pelos imigrantes foi inserida em um novo contexto, de língua de raiz romana. A parit da imigração ocorreu, portanto, um contato linguístico entre duas raízes bastante distintas. Com o "isolamento" linguístico dos imigrantes, ocorreu um novo direcionamento na evolução da língua dos imigrantes, que passam a inserir (agregar por meio de germanização e simples apropriação de palavras da língua portuguesa à língua por eles falada) elementos da língua local na sua prática cotidiana. O presente poema é um exemplo dessa "mistura" linguística, por vezes até exagerada. Um dado interessante que exemplifica essa questão é que ao final do poema é apresentado um glossário, possibilitando ao leitor da língua alemã uma 
Estar entre mundos e ao mesmo tempo não pertencer a nenhum. O caso da literatura em língua alemã produzida no Brasil no século XIX | 165 melhor compreensão do poema tão cheio de termos da língua portuguesa. A seguir pode-se ver o glossário.

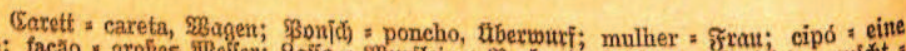
Siane; facto : grobes \$ilefier; Sajio = Wurfleine; Barbant; = barbante, Strid; es pul dit:

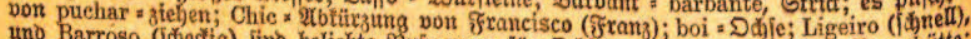
uno Barroso (iđjectig) imo beliebte ఇittinamen für Ddfen;

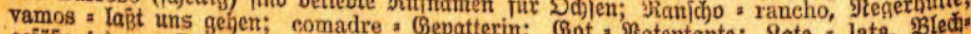

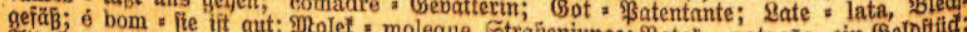

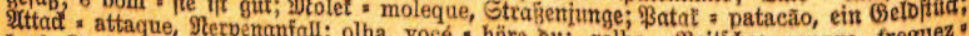
tauf, Sunbe; promotor : Ctall; olha, vocé = höre ou; relho, \$eitidje; compra, freguez."

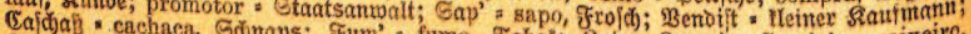

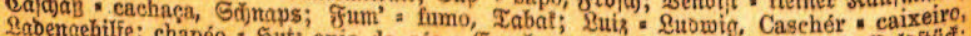

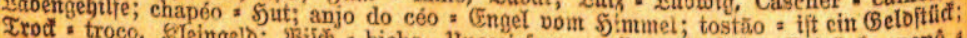

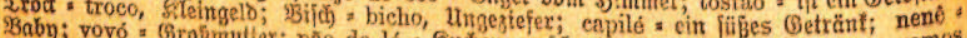
embora - wis wollentitex; pão de $1 \delta$ = Futujen; es lajegt = von ehega, es it gemug; vamos 5jerr; farin .

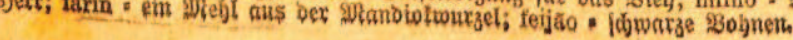

Quanto à forma, é um poema longo, composto de 33 estrofes, cada uma de quatro versos. $\mathrm{O}$ autor procura empregar rimas finais, como se pode ver na estrofe a seguir, ao rimar Stra $\beta$ e Ferraz, Sophie e Marie.
Corre à rua
Es gilt auf die Straß'
Comadre Ferraz
Comadre Ferraz,
A Kathrin, Sophie, die Kathrin, Sophie,
A Madrinha e a Marie.
Die Got und Marie.

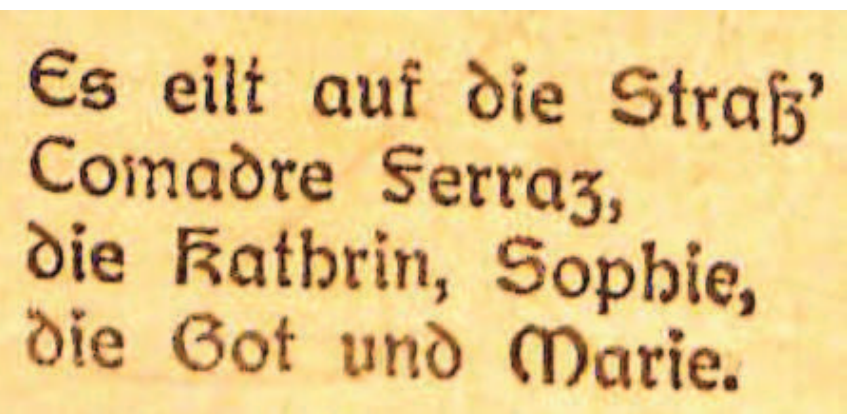

Nem sempre a rima se dá de modo satisfatório, mas na construção do poema busca-se trazer uma aproximação. Imagina-se que tais poemas tenham sido escritos para serem declamados, o que se explica, pois a rima final dá um tom mais musical ao poema, além de facilitar na memorização do mesmo.

Por achar importante a apresentação do poema na sua íntegra, optou-se por inseri-lo no corpo do texto, de modo que possa ser usado e lido por mais pessoas, um dos objetivos do presente trabalho. 


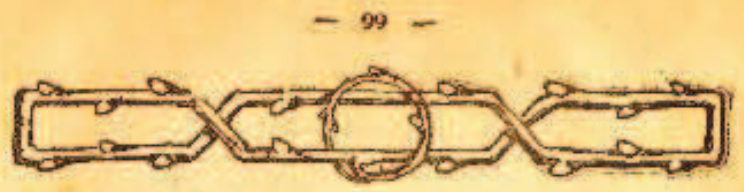

\section{Die Schmier.}

\section{Eili tlogranobenser Strafrenblto in Versen}

von tsarl 5ermann.

Ea backt in Det Carelt brasiliecb und nett Senbort Loni aus Gravatahỵ.

Genber ADamar rkit Ponseb unò Jigar' trabt frob nebenher hei Eeinter (Muliser.

Das Bambursgeflecht ves Wagens ist scleat.

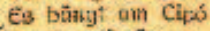

Sucto una Cosso.

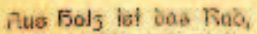
recht klobig tmo plail. Der 5und an Bacbant blickst traurig ins Cane.

Es puscht eint Daar Boi gemiditio und zreu unis gar nitbt mal felt ale stumpe Ccrett.

Votn schrei.et dev Clsh und stidst mit Gosdvidi die epitzige Stong? conn Eot in dis Stans.

. Congito: Darros!

万onit vomos! ran fos! Es gelst nade ber Giast, sie Fansdios nicht Jat:
Es quietsdbt oie Carett e:in lustig Sonett. Sie kreischt and sle piept. Chic, Bai uno Der 5uno aie screit tubs alo quiekt: oio balten den Mund, -

(Uih, 5dmied! uils, Stbmier verkauten wir bier! Die sibmier tist fein bidk und ofic wie Thasic,"

Ês eili auf D̀e Strat̂́ Comedre Servas, Oic Fatbrin, Saphie, Die Bact und (Darte.

Síg gudaen sict salt an dor Sidmier in der Sc,k und hosten bavon und toien: ${ }_{n} \mathrm{E}^{\prime}$ bem."

Die Kurre sie titast uro st5baet und kräidist: ¿Uib, Sdmier! wib, Sdonles weskaufen wi: bior !"

"the, compra, irequez, sär oteibla (Dilreis ?* so seridat der Senbor zun be:m promotox.

Der, kubt twie ein Gap': Ith kau? o.x nicots abl verlikis ar die Stell? goas brummig und sdsuell.

Es komnt ber sopsteis streit laut nno seiar keti: „Die Stanier isi wie kJids: sie toraht fa gat six.

Den: Jon̄ว, det Venòiai, geriectin er fot, kerkozust wai beri Sef eir Clsabsea fiestats

5e, keineo Patel " " Len Isecru floomor. Die brïuluibe W'a' eitaribet as fram 10ैr Cefl uns sir sum?

„O slow, veet, nolcque jooe,

id hou' ole wit ket: tien Grotem haputt?
Luis, zer Cascter, beyirist and viet Cle? Genlasen Emi cus Crazoiabs. 
Estar entre mundos e ao mesmo tempo não pertencer a nenhum. O caso da literatura em língua alemã produzida no Brasil no século XIX | 167

\section{Conclusão}

No momento em que se busca respostas em relação à homogeneização cultural e refletir sobre questões relativas à identidade, é válido lançar um olhar ao passado muitas vezes não muito remoto.

O propósito do presente texto foi, portanto, apresentar uma reflexão sobre a literatura produzida e publicada em língua alemã no Brasil, tomando-se principalmente como período o século XIX. Além de apresentar a literatura - e espera-se que de certa forma alguns já tenham conhecimento dessa rica bibliografia que existe no Brasil -, quer-se estimular e convidar colegas e interessados a participarem nas pesquisas em torno do tema. Nesta pesquisa há muitos elementos pessoais em consonância com os científicos e isso pode ser reforçado neste momento, pois, para uma efetiva participação no projeto e de modo geral na pesquisa, é importante o domínio do idioma alemão (geralmente a referência ao idioma alemão está para a prática de dialetos). Dado o fato que aqui se escreve a um público de formação germanística, espera-se conseguir alcançar potenciais leitores interessados no tema e ter retorno.

\section{BIBLIOGRAFIA}

ANDERSON, Benedict. Comunidades Imaginadas. Reflexões sobre a origem e a difusão do nacionalismo. Trad. Denise Bottman. São Paulo: Companhia das Letras. 2008.

BHABHA, Homi K. Die Verortung der Kultur. Mit einem Vorw. von Elisabeth Bronfen. Dt. Übers. von Michael Schiffmann und Jürgen Freudl. Tübingen: Stauffenburg-Verl., 2000.

BONOW, Irmgart G. Onde o sabiá canta e a palmeira farfalha: a poesia em lingua alemã publicada nos anuários (1874-1941) sul-rio-grandenses. Porto Alegre: Pontifícia Universidade Católica - PUC-RS, 1991, Dissertação (Mestrado em Letras). PUC-RS, 1991.

ETTE, Ottmar. Literatur in Bewegung. Raum und Dynamik grenzüberschreitenden Schreibens in Europa und Amerika. Göttingen: Verbrück Wissenschaft, 2001.

ETTE, Ottmar. ZwischenWeltenSchreiben. Literaturen ohne festen Wohnsitz. Berlin: Kadmos, 2005. 
FAUSEL, Erich. Literatura Rio-Grandense em língua alemã. In: Enciclopédia Rio-Grandense. Vol II - O Rio Grande Antigo. Canoas: Ed. Regional, 1956, p. 222-239.

FLEISCHER, Marion. Elos e Anelos da Literatura em Lingua Alemã no Brasil. São Paulo: Ed USP, 1981.

GUTJAHR, Ortrud. "Transkulturalität und Intermedialität in der Germanistik des globalen Zeitalters. Eine Einleitung”, in: Ortrud Gutjahr (Hg.): Transkulturalität und Intermedialität in der Germanistik des globalen Zeitalters, Panel 2 in: Akten des XII. internationalen Germanistenkongresses Warschau 2010. Vielheit und Einheit der Germanistik weltweit, Band 2: Eröffnungsvorträge Diskussionsforen, hg. v. Franciszek Grucza, Frankfurt a. M. 2012, S. 75-106

HALL, Stuart. Da diáspora. Identiades e mediações culturais. Org. Liv Sovik; Trad. Adelaine La Guardia Resende, Belo Horizonte: UFMG, 2009.

HERMANN, Karl. Die Schmier. Ein riograndenser Straßenbild. In: Kalender für die Deutschen in Brasilien. São Leopoldo: Editora Rotermund, 1915, p.99-100.

HUBER, Valburga. Saudade e esperança. Blumenau: Ed. FURB, 1993.

HUBER, Valburga. "O sentimento patriótico na literatura teutobrasileira". In: Blumenau em Cadernos, v. 44, n. 1/2, p. 52-60, 2003.

KREUTZ, Lúcio. Material didático e currículo na escola teuto-brasileira. São Leopoldo: Ed. Unisinos, 1994.

KUDER, Manfred. Die deutschbrasilianische Literatur and das Bodenständigkeitsgefühl der deutschen Volksgruppe in Brasilien. Ibero Amerikanisches Archiv, v. 10, n. 4, p. 394-494, 1936/37.

NEUMANN, Gerson Roberto. „Eine literatur ohne festen Platz: die suche nach einer Definition." In: Hernández, Isabel ; Vedda, Miguel (Hrsg.). Ibero-americanisches Jahrbuch für Germanistik, Berlin: Weidler, 2012. p. 189-202.

NEUMANN, Gerson Roberto. Brasilien ist nicht weit von hier! Die Thematik der deutschen Auswanderung nach Brasilien in der deutschen Literatur im 19. Jahrhundert (1800-1871). Frankfurt am Main/ Berlin: Peter Lang, 2005.

NEUMANN, Gerson R. A Muttersprache (lingua materna) na obra de Wilhelm Rotermund e Balduino Rambo e a construção de uma identidade cultural híbrida no Brasil. Dissertação de Mestrado. UFRJ, 2000. 
Estar entre mundos e ao mesmo tempo não pertencer a nenhum. O caso da literatura em língua alemã produzida no Brasil no século XIX | 169

NIPPERDEY, Thomas. Deutsche Geschichte 1800 - 1866. Stuttgart: Europäische Bildungsgemeinschaft, 1985.

PAGNI, Andrea. "Literarische Vermittlungen: Bilder des Anderen", in: Peter Birle (Hrsg.): Die Beziehungen zwischen Deutschland und Argentinien. Frankfurt a.M.: Vervuert 2010.

ROTERMUND, Wilhelm. "Unterm südlichen Kreuz" In: Deutsche Post, 4 de janeiro de 1899. São Leopoldo: Editora Rotermund.

RÜRUP, Reinhard. Deutschland im 19. Jahnhundert: 1815 - 1871. Göttingen: Vandenhoeck und Ruprecht, 1984. (Deutsche Geschichte; Bd. 8).

SAID, Edward W. Reflexões sobre o exilio e outros ensaios. São Paulo: Companhia das Letras, 2003.

SEYFERTH, Giralda. "A idéia de cultura teuto-brasileira: literatura, identidade e os significados da etnicidade." In: Horizontes Antropológicos. vol.10 no.22 Porto Alegre July/Dec. 2004.

SOETHE, P. A. Germanistik in Südbrasilien. In: Deutsche Schillergesellschaft. Jahrbuch, v. 54, p. 531-534, 2010.

SOUSA, Celeste H. M. Ribeiro de - Do cá e do lá: Introdução à imagologia. São Paulo, Humanitas/Fapesp, 2004.

Recebido em: 15 de maio de 2016.

Aceito em: 10 de dezembro de 2016. 